\title{
Use of serious games for creating awareness about social enterprises
}

\author{
Bharat Damani $^{1}$ (D) Vishal Sardeshpande ${ }^{1} \cdot$ \\ Uday Gaitonde ${ }^{2}$
}

Received: 1 July 2015/Revised: 10 August 2015/Accepted: 11 August 2015/

Published online: 21 August 2015

(C) Beijing Normal University 2015

\begin{abstract}
India has 3.17 million registered not-for-profit social enterprises with an estimated 83.3 million people engaged with them as employees or volunteers. In the absence of a widespread formal education system for social enterprises, learning by experience has been the main knowledge driver. In recent years, the social sector has drawn more people towards it. The present authors have designed a board game to create awareness about social enterprises. A pilot run, with 48 participants in the age group of 15-74 years, conducted in India, indicates that the challenge before the social sector in India is to create awareness and image building of the sector, to conduct training and workshops, attract more people and organizations to participate in their activities, and possibly make it an integral part of the education system. The board game version can be adopted in electronic format for a wider reach. In a vast country like India, the latter game version can also overcome the traditional barriers of education, language, cost and time to spread awareness on social issues. The social entrepreneurship board game shows the effectiveness of serious games for awareness creation and its potential to impact the thought process. It is an effective method of learning for topics and subjects, in which people normally would not invest in terms of time, efforts and money. This is corroborated by the
\end{abstract}

Bharat Damani

damanibharat@gmail.com

Vishal Sardeshpande

vishal.sir@iitb.ac.in

Uday Gaitonde

gaitonde@iitb.ac.in

1 Centre for Technology Alternatives for Rural Areas (CTARA), Indian Institute of Technology (IIT) Bombay, Mumbai, India

2 Department of Mechanical Engineering, Indian Institute of Technology (IIT) Bombay, Mumbai, India 
FloodSim experience in London which used a serious game for a similar objective. Serious games could be designed to address specific social issues like civic discipline, sanitation, health, hygiene, water, power, and environmental protection.

Keywords Social enterprises - Social entrepreneurship - Board game · Serious games $\cdot$ Creating awareness

\section{Introduction}

India is a developing country with a population in excess of 1 billion people with about $68 \%$ residing in rural areas (Ministry of Home Affairs, Government of India 2014). There are 3.17 million registered not-for-profit institutions (social enterprises) in India having an average work force of 26 people (MOSPI 2012). This translates to an estimated 83.3 million people engaged in their activities, many of whom are not diploma or graduate degree holders. There are very few institutions in India which teach about social enterprises and entrepreneurship. Learning by experience has been the main knowledge driver of those engaged with social enterprises. Given these numbers, there is a need to educate people and create awareness about social enterprises.

The Internet age and technological advances have penetrated the country. Serious games or games designed with defined educational objectives, which can be used for online or offline learning, provide an interesting alternate learning tool for this sector. The FloodSim experiment conducted in London (Rebolledo-Mendez et al. 2009), about the flooding situation there, shows that serious games are an effective tool to spread awareness about social issues. The present authors created a board game to create awareness about social enterprises and how to make them successful. A pilot run was conducted with 48 diverse participants with 4-5 participants per play. A backdrop of social enterprises and entrepreneurship, an overview of serious games, the social enterprise situation in India, the design of the social entrepreneurship game and outcomes of the pilot run are presented here.

\section{Literature review}

\section{Social enterprises and entrepreneurship}

Social enterprises can be not-for-profit or for-profit organizations. Not-for-profit social enterprises like Greenpeace International, include non-government organizations (NGOs) and Trusts which do not have a product or service that generates revenue. Not-for-profit organizations like Aravinda Eye Hospital may have revenue and surplus, but do not distribute the surplus to the owners. For-profit social enterprises like Grameen Bank have a strong social objective and are set up with the objective of becoming financially self-sufficient.

Table 1 captures some literature on social enterprises and entrepreneurship. The overwhelming social problems and challenges and the complex social framework 
Table 1 Literature on social enterprises and entrepreneurship

\begin{tabular}{ll}
\hline Authors & Concept of social enterprises and entrepreneurship \\
\hline Bornstein & Social enterprises find innovative solutions to social problems \\
& Social entrepreneurs are transformative forces: people with new ideas to \\
& address major problems, who are relentless in the pursuit of their \\
& vision, people who simply will not take 'no' for an answer and who \\
& will not give up until they spread their ideas as far as they possibly can \\
& (Bornstein 2004)
\end{tabular}

Certo and Miller

Dees

Light

Morino

Roberts and Woods

Seelos and Mair

Short, Moss and Lumpkin

Thompson

Thompson, Slvy and Lees

Zahra, Gedajlovic, Neubaum and Shulman
Social enterprises combine the elements of business and volunteer sectors (Certo and Miller 2008)

In order to create lasting solutions to social problems, it would be wise to adopt business methods and market-oriented approaches (Dees 2008)

Social entrepreneurship is not a function of the personality alone and depends more on teachable skills, the ability to activate the public, raise capital, negotiate results and manage difficult transitions of growth to maturity. If such aspects are taught, social entrepreneurship could attract more entrepreneurs (Light 2006)

A social entrepreneur has impatience with the status quo and traditional thinking. They have the capacity to get things done and to make things happen. They possess an obsessive compulsion or, some say, an irrational drive, to make vision a reality. They have a sharp focus on results rather than the process and a need or want, not just a desire, for creating the "big impact" (Morino 2007)

Social enterprise is the construction, evaluation and pursuit of opportunities for transformative social change carried out by visionary, passionately dedicated individuals (Roberts and Woods 2005)

Social entrepreneurship creates new methods and models to provide products and services that satisfy basic human needs untouched by the authorities and existing framework of economic and social institutions (Seelos and Mair 2005)

Success of social enterprises could be measured as an outcome or social impact to ascertain what the enterprise gives back to society in terms of job creation and innovation. It could also be measured in terms of the processes or resources used to improve the enterprise success including the social mission, entrepreneur characteristics and the industry structure (Short et al. 2009)

Social entrepreneurship is a hybrid form of enterprise wherein social and cultural needs of society are addressed with a sustained cash flow using the approach, tools and techniques of the commercial for-profit enterprise (Thompson 2002)

Social entrepreneurship demands talent, temperament and sustaining capacity with appropriate training to keep the wheels rolling. They also have their drawbacks and shortcomings in terms of being transparent, responding to scrutiny and questioning, being focused on the short term and wanting to take all the credit (Thompson et al. 2000)

The success of social entrepreneurship is the measurement of total wealth creation. It is the sum of the economic and social wealth creation and has tangible and intangible outcomes such as wealth, happiness and general well-being (Zahra et al. 2009) 
make social entrepreneurship a daunting task. However, the social solutions implemented are innovative answers based on the local needs and resources available.

Not-for-profit social enterprises fund their operations from donations, charities, grants, aid and philanthropy. A harsh economic context increases the demand for social service while philanthropic donations are more difficult to procure in economically challenging times (Austin et al. 2006). Fund limitations often make them sacrifice on the number or nature of social projects or initiatives they can undertake. However, while charity and philanthropy may relieve the symptoms of severe poverty but it does not provide a lasting solution. Muhammad Yunus, the founder of Grameen Bank and 2006 Nobel Laureate, believes charity can be downright harmful. It perpetuates poverty by taking the initiative away from the poor (Yunus and Weber 2010).

Dees and Anderson (2003) recommend for-profit social entrepreneurs be clear and perseverant about their social and economic objectives, but remain flexible and transparent about the strategies to achieve them. They should have goal clarity, objective performance measurement and people with integrity and transparency to overcome criticism and political adversaries. According to Michael Porter (Economist 2006), social enterprises are decades behind business in applying rigorous thinking to the use of money; they can be transformed by learning from the world of business.

There are no official statistics available on the number of social enterprises or the number of people employed or engaged with them. This is due to the absence of a uniform definition of social enterprises and the alternate legal registrations possible in various countries which merge for-profit social enterprises with commercial organizations. In the United Kingdom, the number of social enterprises is estimated at 688,200 with 2.1 million people engaged with them on full-time basis (BMG Research 2013). The United States has more than 1.3 million social enterprises which engage more than 12.5 million people (Leviner et al. 2007). India has 3.17 million registered social enterprises (MOSPI 2012) estimated to engage 83.3 million people. In contrast, only a few educational institutions in India offer formal courses to teach about social enterprises.

In summary, social entrepreneurs are ambitious, mission driven, strategic, resourceful, innovative, and result oriented people. They plunge into their mission and learn along the way, categorizing themselves into a unique league of people which makes it difficult for others to emulate or follow. While many institutions teach commercial or business entrepreneurship, very few teach about social entrepreneurship. There is a strong need to create awareness and impart skills to run a social enterprise (Light 2006; Thompson et al. 2000; Dees and Anderson 2003; Economist 2006) and enable this sector to perform and grow in a structured manner.

\section{Serious games}

Serious games are those that are designed with a purpose other than pure entertainment. They have an educational and learning aspect and are not used just for entertainment purposes (de Freitas and Liarokapis 2014). These games combine 
the elements of entertainment with defined educational objectives. They are an effective learning tool for students who play and learn from them (Damassa and Sitko 2010).

Games provide not only fun but serious learning in a captivating manner even if commercially available relevant games are used (Bokyeong et al. 2009). They enable the players to become decision makers, experimenting with different ways of thinking, experiencing the subject domain in different ways, creating a platform and capability of future learning and problem solving (Gee 2003). During play, the 'thinking aloud' strategy is the best way of creating problem-solving ability i.e., by discussing game play with other players during break sessions positively affects the problem-solving ability (Bokyeong et al. 2009). Computer games improve the learning motivation if the learning tasks and supports are properly embedded in the game (Chen et al. 2015). An online game approach engages students with full involvement, concentration and enjoyment while improving their learning achievement and attitudes in terms of perceived ease of use and perceived usefulness (Hwang et al. 2012).

Games make learning of concepts appetizing, creating a platform for exchange of their creative thoughts. They help students retain the salient points of the teaching, appeal to different styles of learning, engage students, induce creative and divergent thinking, encourage collaborative problem solving, are an easy means for peer learning, overcome dips in concentration levels, function as creative ice breakers and are agents of innovation (Boyle 2011).

Serious games provide a contextualized experience facilitating learning through practice, failure, reflection, repetition and experimentation (Whitton 2012). They create active and engaging environments for learning, which support problem solving, communication and group activities. Noble (2005) states that simulations generate creative emotional tension encouraging the players to explore, conceptualize, inquire, experiment and critically analyse while using multiple senses, reducing the fear of the unknown, enabling the discovery of new possibilities for action. At times, simulations create conditions where the learning content is greater than the teaching content and learners learn more than they are taught.

Zagal et al. (2006) state that serious games can be categorized as competitive, cooperative and collaborative games. They can be played in board form or on the computer or a smartphone. Board games are cheaper to make, simpler and transparent, but require the players to be physically present at the same time in one place. Creating computer- or smartphone-based games is expensive and technology intensive, but such games can conduct sophisticated analysis during play and display the results effectively. They also have greater player flexibility overcoming the barrier of physical presence in one place and facilitating play during nonproductive times like travel.

Games for learning should have six dimensions of fantasy, rules/goals, sensory stimuli, challenge, mystery and control, making instructional games like the SimCity series instructive, engaging and enlightening; debriefing at the end of the game establishes the bridge between game experiences and learning (Garris et al. 2002). Simulation technologies are powerful educational tools especially where individuals or teams are given constructive feedback on their performance for a 
given scenario in a simulated environment. Serious games, once designed, can be converted to different languages with ease using an audio-visual interface. With smartphones and social media, spreading the game across the country is quick and easy. Serious games can address people who have mobile phone or computer access, overcoming the traditional barriers of education, language, cost and time. It also provides a playful and non-threatening way to learn about important issues. The key to games is content design and strategizing for the desired impact.

\section{Use of serious games for social enterprises and the FloodSim experiment}

Social enterprises are an amalgam of the social entrepreneur and the social entity created. In small organizations, the social entrepreneur represents the social entity. The traits of the social entrepreneur create the social entity's style of functioning. However, a sustainable social enterprise must transcend beyond the individual traits of the social entrepreneur and embody organizational characteristics. Likewise, the beneficiaries have their own characteristics around which the social enterprise must function in a sector of choice. These are represented in Fig. 1. The social enterprise and the beneficiaries can be effectively linked and brought closer using serious games as a tool to create awareness, simplify learning, mobilize participation and create the desired social impact. Serious games are available for schools and as an alternate to education, generally with a target segment in the age group from 4 to 16 years. For the higher age groups, games like RescueSim, SimPort, Building Detroit, America's Army (for recruitment in the army), Renault Academy (for training salesmen and dealers), CancerSpace, RealLives 2010, SimVenture and SandBox Serious Games have been developed (de Gloria et al. 2014).

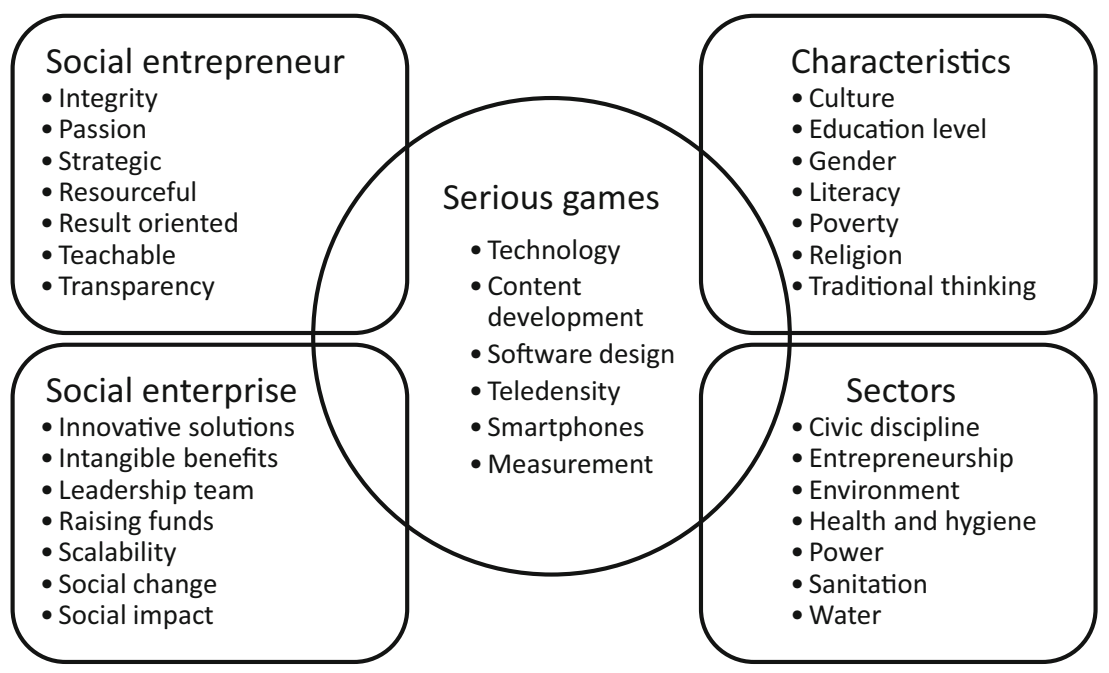

Fig. 1 Role of serious games 
FloodSim is a serious game designed to spread awareness about the flooding situation in London (Rebolledo-Mendez et al. 2009). Its objectives are to raise awareness of the flooding issue and to increase citizen engagement. The game makes the player take the role of a flood policy strategist to implement a selection of strategies for addressing the risk of flooding on a pre-defined budget. Players, through a simulation, deal with various elements of flood-related problems and policy in a period of 3 years. The player chooses the type of barriers to build and the funds allocation to maintenance considering building planning, education, warning systems, drainage systems, emergency services and grants. In spite of the simplicity of the simulation, many players considered it an accurate source of information indicating that simulations have the potential to engage people and raise awareness of societal issues.

During a one-month period, 25,701 people played the game with $38.2 \%$ of them being in the $21-30$ years range, $25.7 \%$ in the $31-45$ years range and $22.8 \%$ in the 11-20 years range-collectively representing $86.7 \%$ of the players. This demonstrates the reach of serious games among age groups. The results suggest FloodSim was hugely successful in generating general public interest, increased awareness and educated people about flood risk and prevention.

The FloodSim experiment highlights the potential of serious games to engage users with serious topics while raising public awareness and understanding of social issues such as flooding and related policymaking through experiential learning. Serious games have the potential to engage large number of people to increase awareness of important societal issues, amongst sections of the population that would otherwise not be motivated to explore them. It is only recently that serious games have been developed to create awareness of social problems, such as the impact of flooding.

Digital game audiences are expanding rapidly: gaming is almost ubiquitous among young people and is reaching older age groups, with social, casual and intense forms of gaming appealing to women and men alike, especially with new devices, such as smart phones and tablets, and new ways to play games, particularly online, that are changing the face of the gamification industry, estimated at over $€ 2.35$ billion worldwide (Stewart et al. 2013). The FloodSim experience encourages one to think about using serious games as a tool for spreading awareness on social issues and social entrepreneurship in a vast country like India. In India, serious games could be created for the social sector to address issues of civic discipline, sanitation, health, hygiene, water, power and environment protection. They can also address issues of culture, gender, class and religion. Basic education, skills and information on agriculture, science, climate, entrepreneurship, social enterprises, etc., can also be disseminated in a playful and entertaining manner.

\section{The situation in India}

The Government of India report on Non-Profit Institutions in India states that there are 3.17 million registered not-for-profit institutions (social enterprises) in India. Data on registered for-profit institutions working in the social sector is merged with other commercial businesses, and hence, it is not possible to segregate it. In 
addition, there would be many more unregistered not-for-profit institutions and forprofit social enterprises working in the social sector, data for which are not available. It would not be surprising if the total number of social sector institutions in India exceeds 10 million.

This sector attracts an average work force of 26 people per enterprise which translates to 83.3 million people or about $8 \%$ of the Indian population, many of whom are not diploma or graduate degree holders (Ministry of Home Affairs, Government of India 2001). Social enterprises in India typically employ people from the underprivileged segment of the society, leading to increased training and development cost as such people are generally uneducated or unskilled (Singh 2012). The conventional method of formal education in social entrepreneurship is a long process and serves few people who are interested in taking a qualification in the subject. However, for societal benefit, it is necessary to spread awareness of the concept and encourage people to come forward and support the movement.

The government has acknowledged that not-for-profit institutions work at grassroots level even in remote areas and, therefore, their reach is much wider (MOSPI 2012). They are closer to ground realities and know the needs of the communities. Their approach with the target group is direct and emphatic, due to which they are able to draw more contextualized plans of action. They also manage to develop intimate contacts with the people and develop confidence among them.

The Internet age and technological advances have transformed the way people do things. Telecom subscribers in India as of April 2015 total 999 million users, with 580 million being in urban areas and 419 million in rural areas; the urban teledensity is 149 and rural teledensity 48 (TRAI 2015). Avendus Capital (2013) in its report on India's mobile Internet market states there are 36 million smartphone users with 22 million accessing the Internet using a $3 \mathrm{G}$ connection (which increased to 28 million in 4 months from December 2012 to March 2013). According to The Nielsen Company (2013), $81 \%$ of the people in India have a mobile phone with $80 \%$ using feature phones and $10 \%$ using smartphones. $13 \%$ of the smartphone users use apps with games being the most popular (39\% usage), followed by social networking and videos (29\% each). These numbers are increasing rapidly, reflecting how people use technology on a daily basis.

The reach of technology is far and wide, spreading information in a blink. Children seem to find ways to use technology, overcoming conventional barriers of language and formal education (Mitra and Rana 2001). This has also created a plethora of entrepreneurs dedicated to using e-technology to business models and, coupled with the popularity of social media, to address various social issues. This potent combination can be channelized to new ways of learning and education-one such being the field of serious games for the social sector.

Board games and computer games both have their advantages and disadvantages. In a country like India where literacy, reach and cost are important parameters, it may be prudent to have both forms of the game. A board game could be designed, tested and improvised to a mature version based on player feedback in a particular area or region. The mature version could then be converted into a computer version for wider reach and impact. 


\section{Motivation}

Considering the sheer number of social enterprises in India, the people engaged with them and the size of the Indian population, there is a need to create awareness of social enterprises, to reach out to the large number of potential beneficiaries and to equip social entrepreneurs with the skills required to create social impact. The present authors created a solution in the form of a board game. The game aims to serve the purpose of an eye opener to the student, the employed, the business owner, the haves and the have-nots on the importance of contributing to society. It educates the players on the ups and downs of a job and business, encouraging them to also consider being associated with a social enterprise or become a social entrepreneur. It also guides social entrepreneurs on how to make their venture sustainable. The playand-learn method is a fun-filled way of creating awareness; providing people with an encapsulated learning about social enterprises.

The objective of the research is to examine whether a serious game can be used to create awareness and educate people about social enterprises.

\section{Methodology}

The design of the social entrepreneurship game and the methodology followed in the research process are described below.

\section{Social entrepreneurship game design}

The game is designed for people above 12 years of age incorporating the dimensions recommended by Garris et al. (2002). It is suggested that 3-4 people play it together to extract good learning from every play. The game has three boards: the Job board (Fig. 2), the Business board (Fig. 3) and the Social Entrepreneurship board (Fig. 4). The game centres on parameters of earning money (money units-MU), acquiring fame and reputation (rating score-RS), attaining satisfaction or well-being (well being score-WB) and creating societal wealth (society index-SI) through a point system.

The target is to acquire reputation in excess of $100 \mathrm{RS}$ units, achieve satisfaction in excess of $150 \mathrm{WB}$ units and create societal wealth of 300 SI units. These are to be achieved as a combination and not on stand-alone basis. There is no target on the amount of MU earned. However, MU would be required to meet expenses and to execute events, operations, activities and opportunities.

Each game board has 24 spaces comprising three cycles. On completion of every cycle, i.e. passing or landing on the space marked for collecting the pay/earning profit/SI units, each player collects the net income from the bank, and the SI units are accumulated as applicable for the chosen occupation.

Key drivers of a job, business and social activity are identified. Real-time scenarios are captured to simulate a realistic environment. Practices to be adopted and followed are encouraged; those that are detrimental are discouraged through the 


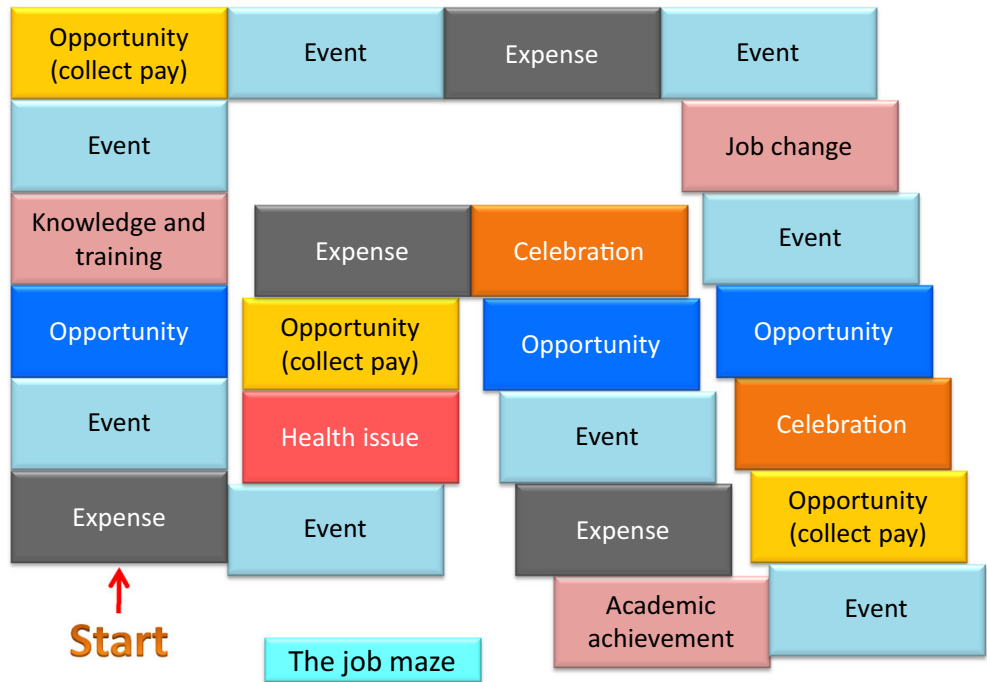

Fig. 2 The Job board

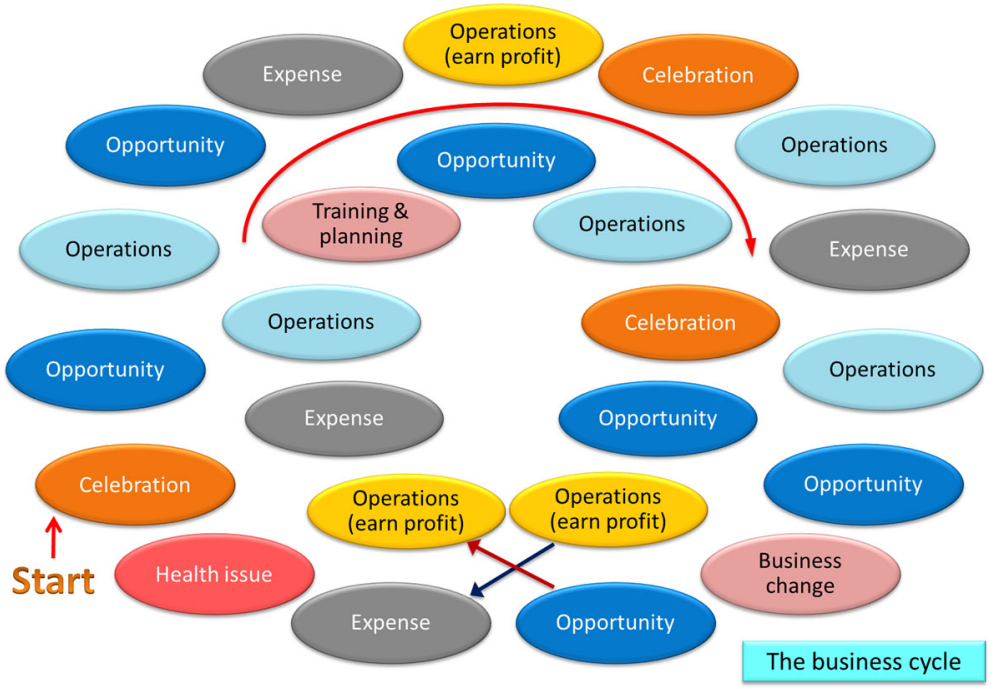

Fig. 3 The Business board

point system. During play, all players are encouraged to adopt a social activity or social entrepreneurship and learn the impact it can create around them.

Each player chooses the board on which to play and selects the occupation they want to pursue to achieve their target. The selected occupation can be changed during play at specific instances, i.e. if they select the option in a card.

Movement on the board happens with the throw of one dice. The advancement on the spaces is equal to the number displayed on the throw of the dice. The spaces depict various incidents encountered in real life and provide the simulation for the 


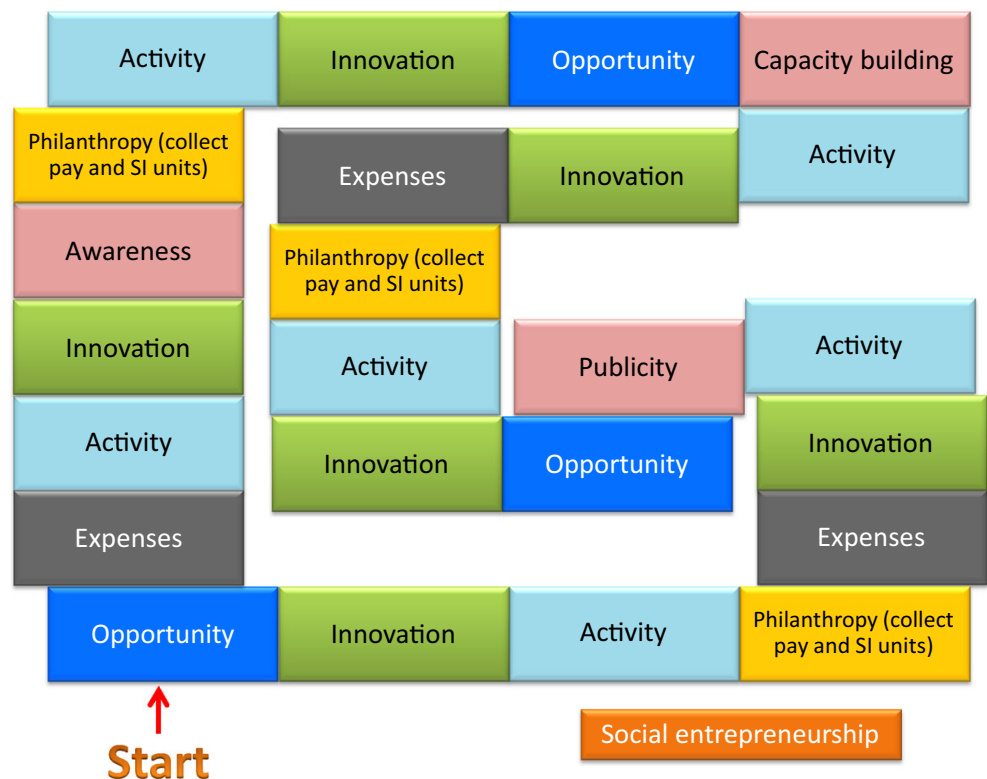

Fig. 4 The Social Entrepreneurship board

player to navigate. Six spaces have incident cards to be drawn and action to be taken as per the description and options on the card. Some cards have standard instructions while some have options for the player to select or decide. A sample of the incident cards is given in Fig. 5.

As the player lands on a space, the space description indicates what the player has to do. They also provide for accretion/reduction of the four parameters that help players reach their target. The cards, incidents and decisions taken will decide the player progress and take them to their target. There is no winner or time limit. On achieving the collective target, the player finishes the game.

\section{Sample}

The pilot run conducted in the cities of Mumbai, Pune and Ahmedabad covered a total of 48 participants. They represent a cross section of age ranging from 15 to 74 years (18 less than 35 years; 30 more than 35 years), gender (31 male; 17 female), qualification (17 bachelors or less; 31 post graduates), rural exposure (31 without; 17 with rural exposure), own association with social enterprises (17 without; 31 with association) and family association with social enterprises (29 without; 19 with association). The sample composition is depicted in Fig. 6.

\section{Research instrument}

The research procedure involved playing the social entrepreneurship game and answering a questionnaire. At the beginning, the facilitator briefs the players on how 
Teaching, coaching, training You teach, coach and train villagers resulting in literacy, capacity building and empowerment. Get 10 RS, 10 WB and 10 SI units. If doing social activity on part-time basis, get half the units.

Activity card

\section{Family events}

There are occasions and events in the family. Your participation is required.

1. Participate actively and on a large scale. Pay $50 \%$ of your net income towards expenses. Get $10 \mathrm{WB}$ and 5 RS units.

2. You participate quietly and conservatively. Pay $25 \%$ of your net income towards expenses.

\section{Expense card}

\section{Expansion}

Business is doing well and you decide to expand. Pay $100 \%$ of your net income for the expansion. Get 10 RS units. Gross income increases by $50 \%$. Net income increases by $10 \%$.

You may decide not to expand. Lose 10 RS units and 5 WB units.

Operations card

\section{Promotion}

Congratulations! You have been promoted. Your gross income and net income increase by $300 \mathrm{MU}$. Also get 5 RS units.

Event card

Water conservation measures Water scarcity and rain uncertainty motivates you to create solutions for water preservation, conservation, better utilization and recycling. Get 10 RS, 20 WB and 20 SI units. If doing social activity on part-time basis, get half the units.

Innovation card

Property - residential (for self-occupation) You have an option to purchase your own house. Pay $200 \%$ of your net income as down payment. Reduce your net income by $40 \%$ for EMI payments. Get 10 RS and 10 WB units. Alternately, you can decide to defer the purchase. Lose 10 WB units.

Opportunity card

Fig. 5 Sample incident cards

Sample composition
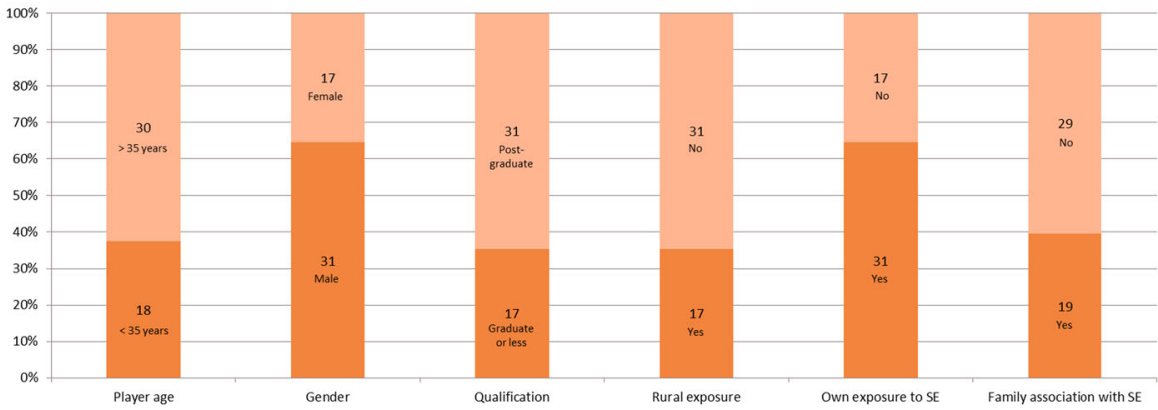

Fig. 6 Sample composition

to play the game and of the play target without giving any indication of the underlying objectives of the game. They are requested to read aloud each incident card as it comes so that all players know what is in the card and the decision, if any, 
taken by the player. During play, the players are free to interact with or consult each other. The facilitator does not guide or influence any such discussion or decision. Each player maintains a player scoring sheet to keep track of the game progress and their respective cumulative score on the parameters. The facilitator ensures the scoring sheet is correctly updated and the play money is properly transacted. The game is played for 20 moves of each player or till all players achieve the target, whichever is earlier. At the end of the game, the facilitator has a debriefing session and answers questions of the players, if any; debriefing has been emphasized by Bokyeong et al. (2009) and Garris et al. (2002).

\section{Research procedure}

Each participant fills a questionnaire, part of it before playing the game and, the remaining part, after playing the game. The questionnaire provides quantitative feedback on a 5-point Likert scale and qualitative information in descriptive form. The quantitative information is analysed by averaging the Likert scores to understand the relative importance of various aspects of social enterprises.

The qualitative information is analysed to understand the mind and thoughts of the players. This information is captured in six classifications, created after assimilating all the qualitative information received. Blank responses, if any, are ignored. These are then totalled to find the percentage response of the players to each of the six classifications.

\section{Results and discussion}

The quantitative and qualitative responses of the players are presented below.

\section{Quantitative responses on Likert scale}

The players responded to 23 questions on a 5-point Likert scale about their views on social enterprises, their intent to associate with a social activity or enterprise and their learning from the game. The average score of each question was calculated. The player views on social enterprises are depicted in Fig. 7.

The current level of awareness about social enterprises reflected an average score of 2.85. They acknowledged their role in human development (average score of 3.88 ), and felt they should be managed by businessmen (4.17) and by professionals (4.27). They felt social enterprises should undertake commercial activity (3.60), depend less on donations and grants (3.58) and rather, generate their own funds (4.42). These findings are consistent with the views of Muhammad Yunus (Yunus and Weber 2010), Dees and Anderson (2003) and Michael Porter (Economist 2006).

Figure 8 captures the player intent to work or associate with social enterprises. The average score of their willingness to start their own social enterprise was 2.65, while their inclination to associate by donating money was 3.23. The average contentment level with their current occupation was 3.11. They felt social enterprises could be a career option (3.73) and were fine working (3.98) or 


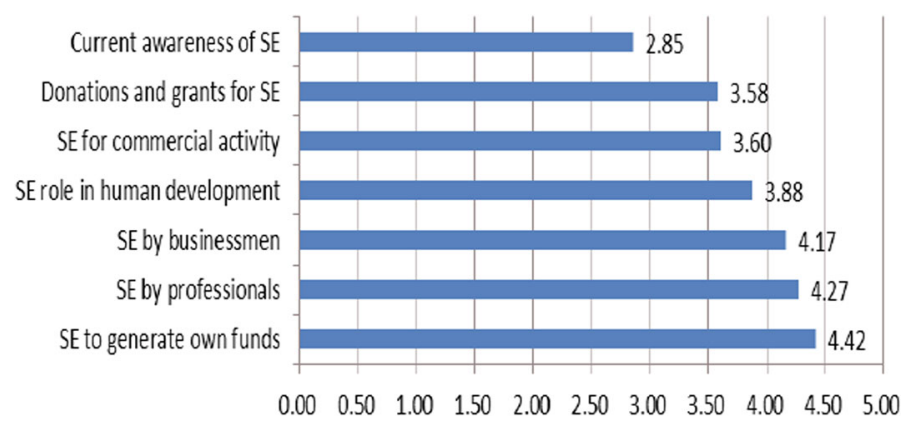

Fig. 7 Player views on social enterprises

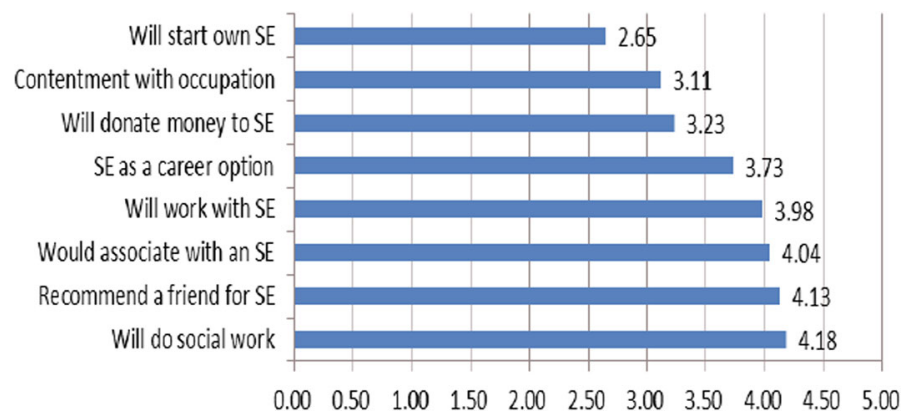

Fig. 8 Player intent for association with social enterprises

associating (4.04) with such organizations. They were more happy to recommend a friend to work or associate with a social enterprise (4.13) and to participate in a social activity (4.18). This supports the views of Bornstein (2004) and Morino (2007) that social entrepreneurs are mission driven and will not take 'no' for an answer and that social entrepreneurship is person dependent (Light 2006) Everyone cannot become a social entrepreneur or would like to be associated with social enterprises.

Figure 9 captures the player responses related to their learning from the board game. The average score of player understanding on what made social enterprises fail was 3.23, and on what made them succeed was 3.65. They got a fair idea about what social enterprises do (3.71), and they wanted to know more about them (4.20). They realized the importance of social enterprises (4.56), and expressed a strong need for formal education about them (4.58). They wanted to play the game again (4.50), and their knowledge takeaway from the game was very high (4.63). This corroborates with the findings of Chen et al. (2015) and Hwang et al. (2012).

\section{Qualitative feedback}

Analysis of the quantitative feedback reveals that players felt (Fig. 10) social enterprises should be promoted by image building of the sector $(22.7 \%)$, through 


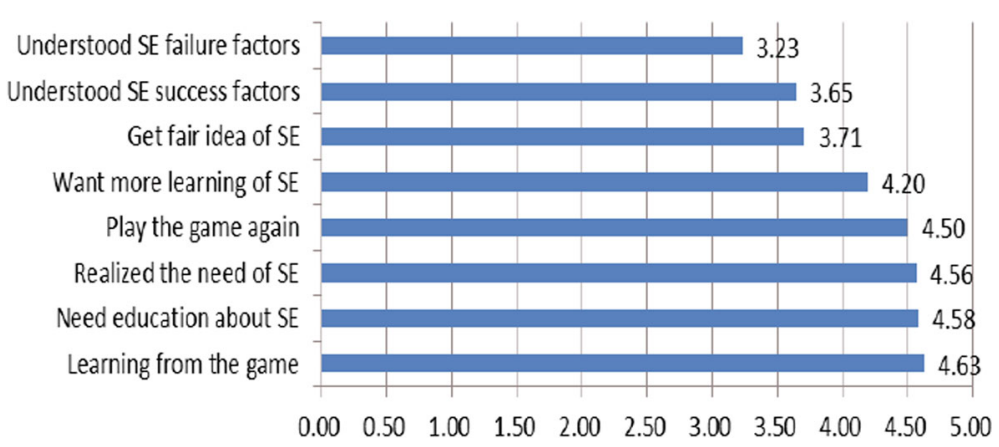

Fig. 9 Player learning from the board game

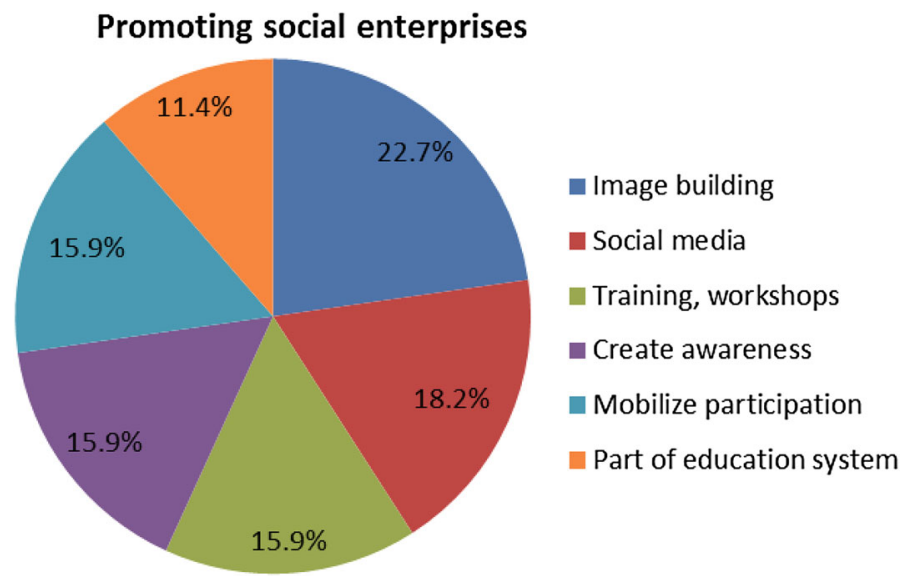

Fig. 10 How social enterprises should be promoted

the use of social media (18.2\%), through training and workshops (15.9\%), through awareness creation (15.9\%), by greater participation in their activities (15.9\%), and by making it an integral part of the education system (11.4\%).

The game analysis (Fig. 11) shows players were impacted by the overall game design $(27.3 \%)$, by the real-life situations encountered during play (18.2 \%), by the option of changing careers midway through their work-life (18.2\%), by the concept of being able to measure life achievements (13.6\%), by the decision-making options $(11.4 \%)$ and the information provided on social enterprises $(11.4 \%)$. This is an outcome of the game design and the dimensions emphasized by Garris et al. (2002) and corroborates with the findings of Whitton (2012) and Noble (2005).

Playing the game was an enlightening experience about social enterprises for the players (Fig. 12) with $25.6 \%$ realizing the importance of adopting a balanced approach to life, $20.9 \%$ stated it was an eye-opener and broadened the mind, $16.3 \%$ got a good understanding of how social enterprises work, $14.0 \%$ realized the importance of social enterprises, another $14.0 \%$ realized the importance of having life goals and $9.3 \%$ appreciated the importance of giving back to society. 


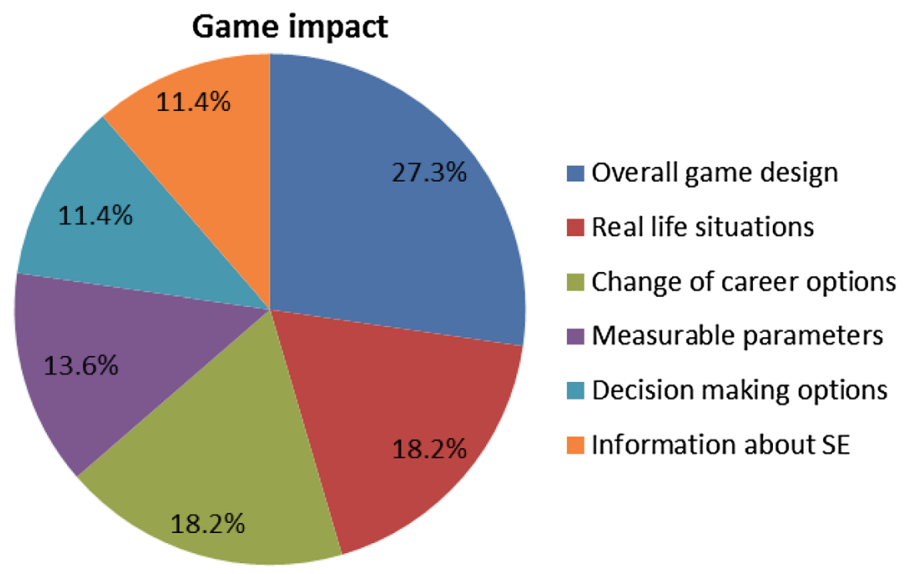

Fig. 11 Nature of the game impact

\title{
Learning from the game
}

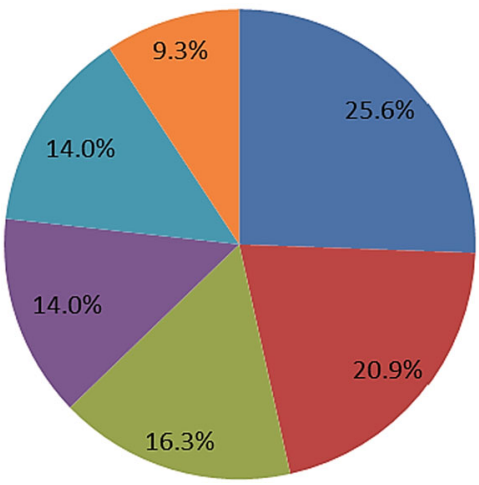

\author{
$\square$ Balanced approach to life \\ $\square$ Mind opener on social \\ enterprises \\ $\square$ How social enterprises \\ work \\ $\square$ Importance of social \\ enterprises \\ Importance of life goals \\ $\square$ Giving back to society
}

Fig. 12 Learning from the game

This confirms the relevance of serious games as expressed by de Gloria et al. (2014) and validates the views of de Freitas and Liarokapis (2014), Damassa and Sitko (2010), Bokyeong et al. (2009), Gee (2003), Boyle (2011) and Noble (2005).

\section{Conclusions}

Serious games have the potential of creating interest and enhance the knowledge takeaways (Bokyeong et al. 2009; Chen et al. 2015; Hwang et al. 2012). They can educate a large number of people in a short time (Gee 2003; Bokyeong et al. 2009; Rebolledo-Mendez et al. 2009). Game play makes the learning exciting and nonthreatening with a higher retention value (de Freitas and Liarokapis 2014; Damassa 
and Sitko 2010; Boyle 2011). With technological advancement and Internet/mobile penetration, serious games have created a new educational opportunity and are a good medium to spread messages and knowledge at a low cost to the beneficiary.

From the player responses, we can say that, while the current level of awareness about social enterprises is low, they acknowledge their role in human development. They suggest that they be managed by businessmen or professionals and should generate their own funds, corroborating the views of Dees and Anderson (2003) and Michael Porter (Economist 2006). Players are not willing to start their own social enterprise. They would rather do social work (part-time or on a one-off basis) or be associated with them in some manner. Working with social enterprises as a career option is fine but, they would rather recommend a friend instead of their joining the social enterprise themselves. By playing the board game, players have realized the importance of social enterprises; they could understand what they do and recommend formal education about them.

$63.9 \%$ of the players expressed a strong need for image building of the sector through awareness creation, mobilizing participation of people and organizations to increase its credibility, and through the education system. They realized what social enterprises actually do and want the work be spread in the right manner by conducting training and workshops, and making the use of social media. $88.6 \%$ of the players were impacted by the game design as it captured real-life situations, had measurable parameters, encouraged the players to change careers and provided decision-making options. $60.5 \%$ of the players became knowledgeably aware about social enterprises, dispelling some misconceptions they had, and $39.5 \%$ realized the need to redefine their approach to life and consider societal benefit as a part of their life goals.

From the pilot of the board game, we can say that the challenge before the social sector in India is to create awareness and image building of the sector, to conduct training and workshops, attract more people and organizations to participate in their activities, and possibly make it an integral part of the education system. The social entrepreneurship board game shows the effectiveness of serious games for awareness creation and impacting the thought process. It is an effective method for topics and subjects, for which people normally would not take the trouble to invest time, efforts, and/or money to learn. An electronic version of the game can help achieve this in quick time, as was experienced in the FloodSim experiment (Rebolledo-Mendez et al. 2009).

From the above observations, we can say that the pilot research confirms that a serious game can be used to create awareness and educate people about social enterprises. Creating serious games for social awareness in specific sectors is an area for further research. A few pilots could be created on specific issues in the social sectors like civic discipline, sanitation, health, hygiene, water, power, and environmental protection. The target segment would be the age group of 10-45 years who have access to the Internet or a smartphone. As people get used to this form of awareness creation and learning, more serious games could be introduced.

Acknowledgments This research has not received any specific grant from any funding agency in the public, commercial, or not-for-profit sectors. 


\section{References}

Austin, J., Stevenson, H., \& Wei-Skillern, J. (2006). Social and commercial entrepreneurship: Same, different or both? Entrepreneurship Theory and Practice, 30(1), 1-22.

Avendus Capital. (2013). India's mobile Internet: The revolution has begun. Mumbai.

Bokyeong, K., Hyungsung, P., \& Youngkyun, B. (2009). Not just fun, but serious strategies: Using metacognitive strategies in game-based learning. Computers \& Education, 52, 800-810.

Bornstein, D. (2004). How to change the world: Social entrepreneurs and the power of new ideas. Oxford: Oxford University Press.

Boyle, S. (2011). An introduction to games based learning. Dublin: UCD Teaching and Learning.

Certo, T. S., \& Miller, T. (2008). Social entrepreneurship: Key issues and concepts. Business Horizons, 51, 267-271.

Chen, C. H., Liu, G. Z., \& Hwang, G. J. (2015). Interaction between gaming and multistage guiding strategies on students' field trip mobile learning performance and motivation. British Journal of Educational Technology,. doi:10.1111/bjet.12270.

Damassa, D. A., \& Sitko, T. D. (2010). Simulation technologies in higher education: Uses, trends and implications. ECAR Research Bulletin, 3, 4-7.

de Freitas, S., \& Liarokapis, F. (2014). Serious games: A new paradigm for education?. Retrieved June 19, 2014, from http://sgi.cueltd.net/publications/papers/SeriousGamesInEd_v6.pdf.

de Gloria, A., Bellotti, F., Berta, R., \& Lavagnino, E. (2014). Serious games for education and training. International Journal of Serious Games, 1(1)

Dees, G. J. (2008). Philanthropy and enterprise: Harnessing the power of business and entrepreneurship for social change. Durham: Duke University.

Dees, G. J., \& Anderson, B. B. (2003). Sector-bending: Blurring lines between non-profit and for-profit. Society, 40, 16.

Economist. (2006). The business of giving. The Economist. Retrieved Oct 15, 2011, from http://www. economist.com/node/5517605/print.

Garris, R., Ahlers, R., \& Driskell, J. E. (2002). Games, motivation and learning: A research and practice model. Simulation \& Gaming, 33(4), 441-467.

Gee, J. P. (2003). What video games have to teach us about learning and literacy?. New York: Palgrave/ St. Martin's.

Hwang, G. J., Wu, P. H., \& Chen, C. C. (2012). An online game approach for improving students' learning performance in web-based problem-solving activities. Computers \& Education, 59, 1246-1256.

Leviner, N., Crutchfield, L., \& Wells, D. (2007). Understanding the impact of social entrepreneurs: Ashoka's answer to the challenge of measuring effectiveness. In Mosher-Williams, R. (Ed.) Research on Social Entrepreneurship: Understanding and Contributing to an Emerging Field (pp. 89-103). http://www.ashoka.org/resource/4784.

Light, P. C. (2006). Reshaping social entrepreneurship. Stanford Social Innovation Review, 4, 47.

Ministry of Home Affairs, Government of India. (2001). Literacy and level of education. Census 2001. Retrieved Oct 11, 2014, from http://censusindia.gov.in/\%28S\%28s5tul34542fv3z451xf43t55\%29\% 29/Census_And_You/literacy_and_level_of_education.aspx.

Ministry of Home Affairs, Government of India. (2014). Census of India, 2011. Retrieved Oct 11, 2014, from http://www.censusindia.gov.in/2011census/PCA/PCA_Highlights/pca_highlights_file/India/ 5Figures_at_glance.pdf.

Mitra, S., \& Rana, V. (2001). Children and the Internet: Experiments with minimally invasive education in India. The British Journal of Educational Technology, 32(2), 221-232.

Morino, M. (2007). Business entrepreneurs and philanthropy: Potential and pitfalls. Legacy 2007. National Philanthropic Trust.

MOSPI. (2012). Non-Profit Institutions in India-A profile and Satellite Accounts in the framework of System of National Accounts. New Delhi: Ministry of Statistics and Programme Implementation (MOSPI), Government of India.

Noble, S. (2005). Understand adult learning and development: Practice in simulated realities. In D. Ulrich, L. Carter, M. Goldsmith, \& D. Saini (Eds.), The Change Champion's Fieldguide-Strategies and tools for leading change in the new era (pp. 194-217). New Delhi: Excel Books. 
Rebolledo-Mendez, G., Avramides, K., de Freitas, S., \& Memarzia, K. (2009). Societal impact of a serious game on raising public awareness: the case of FloodSim. In Proceedings of the 2009 ACM SIGGRAPH Symposium on Video Games. New Orleans (pp. 15-22).

Research, B. M. G. (2013). Social enterprise: Market trends. United Kingdom: Cabinet Office.

Roberts, D., \& Woods, C. (2005). Changing the world on a shoe-string: The concept of social entrepreneurship. University of Auckland Business Review, 7, 45-51.

Seelos, C., \& Mair, J. (2005). Social entrepreneurship: Creating new business models to serve the poor. Business Horizons, 48, 241-246.

Short, J. C., Moss, T. W., \& Lumpkin, G. T. (2009). Research in social entrepreneurship: Past contributions and future opportunities. Strategic Entrepreneurship Journal, 3, 161-194.

Singh, P. (2012). Social entrepreneurship: A growing trend in Indian economy. International Journal of Innovations in Engineering and Technology, 1(3), 44.

Stewart, J., Bleumers, L., Looy, J. V., Mariln, I., All, A., Schurmans, D., et al. (2013). The potential of digital games for empowerment and social inclusion of groups at risk of social and economic exclusion: Evidence and opportunity for policy. Seville: Joint Research Centre, European Commission.

The Nielsen Company. (2013). The mobile consumer: A global snapshot. New York: The Nielsen Company.

Thompson, J. (2002). The world of the social entrepreneur. The International Journal of Public Sector Management, 15(5), 412-431.

Thompson, J., Slvy, G., \& Lees, A. (2000). Social entrepreneurship-A new look at the people and the potential. Management Decision, 38(5), 328-338.

TRAI. (2015). Press Release No. 37/2015. New Delhi: Telecom Regulatory Authority of India (TRAI).

Whitton, N. (2012). The place of game-based learning in an age of austerity. Electronic Journal of e-Learning, 10(2), 249-256.

Yunus, M., \& Weber, K. (2010). Building social business: The new kind of capitalism that serves humanity's most pressing needs. New York: PublicAffairs.

Zagal, J. P., Rick, J., \& His, I. (2006). Collaborative games: Lessons learned from board games. Simulation and Gaming, 37(1), 24-40.

Zahra, S. A., Gedajlovic, E., Neubaum, D. O., \& Shulman, J. M. (2009). A typology of social entrepreneurs: Motives, search processes and ethical challenges. Journal of Business Venturing, 24, 519-532.

Bharat Damani received his B.Tech. (Mechanical) degree from IIT Kanpur in 1984 and Master of Management Studies (MMS) in Finance from Mumbai University (1986) and is awaiting Ph.D degree conferment (nearing completion-expected around second-half of 2015) from IIT Bombay. He has so far gained 28 years of combined experience through working/associating with organizations like the State Industrial and Investment Corporation of Maharashtra (SICOM) Limited, The Sakura Bank Japan, Sumitomo Mitsui Banking Corporation Japan, McKinsey \& Co, Tata Capital, A.T.E. Enterprises and Sakal International Learning Centre. His research areas of interest include social enterprises and ENTREPRENEURSHIP; and nurturing entrepreneurs and making their enterprise sustainable.

Dr. Vishal Sardeshpande received his M.Tech. in 2000, and Ph.D. in 2006 from IIT Bombay, and B.E. in 1996. His work experience includes working with organizations like Thermax, Genesys International, EcoAxis Systems and A.T.E. Enterprises for 16 years in the fields of energy systems, energy optimization, solar energy, technology applications in rural areas, and nurturing social enterprises and entrepreneurs. He is a faculty member at CTARA, IIT Bombay. His research areas of interest include energy optimization, solar thermal energy systems, technology in rural areas, and social enterprises.

Dr. Uday Gaitonde received his B.Tech (Mechanical) in 1973 and Ph.D. in 1977 both from IIT Bombay. He was earlier employed with Bharat Heavy Electricals Limited before joining IIT Bombay, where he has beeen working as a faculty member since 1980. His research areas of interest include thermodynamics; experimental and numerical investigations in heat transfer; design and analysis of components of power plants; heat-transfer problems in industry; and safety studies related to Indian nuclear power plants. 